\title{
Prognostic role of neutrophil lymphocyte ratio in patients with spontaneous intracerebral hemorrhage
}

\author{
Jing Zhang ${ }^{1, *}$, Linrui Cai ${ }^{2, *}$, Yanlin Song ${ }^{3, *}$, Baoyin Shan ${ }^{1}$, Min He ${ }^{1}$, Qingqing Ren ${ }^{1}$, \\ Chaoyue Chen ${ }^{1}$, Zhiyong Liu ${ }^{1}$, Yunhui Zeng ${ }^{1}$ and Jianguo $\mathrm{Xu}^{1}$ \\ ${ }^{1}$ Department of Neurosurgery, West China Hospital, Sichuan University, Chengdu 610041, PR China \\ ${ }^{2}$ National Drug Clinical Trial Institute of West China Second University Hospital, Sichuan University, Chengdu 610041, PR \\ China \\ ${ }^{3}$ West China School of Medicine, West China Hospital, Sichuan University, Chengdu 610041, PR China \\ *These authors have contributed equally to this work \\ Correspondence to: Jianguo XU, email: jianguo_1229@126.com \\ Keywords: neutrophil lymphocyte ratio, intracerebral hemorrhage, prognosis, outcome \\ Received: May 23, $2017 \quad$ Accepted: July 30, $2017 \quad$ Published: September 08, 2017 \\ Copyright: Zhang et al. This is an open-access article distributed under the terms of the Creative Commons Attribution License 3.0 \\ (CC BY 3.0), which permits unrestricted use, distribution, and reproduction in any medium, provided the original author and source \\ are credited.
}

\section{ABSTRACT}

The aim of this study was to evaluate the prognostic role of neutrophil lymphocyte ratio (NLR) in patients with spontaneous intracerebral hemorrhage (ICH). PubMed, EMBASE, Web of Knowledge, Cochrane Library and China National Knowledge Infrastructure were searched for potentially relevant literature. The study and patient characteristics were extracted. Odds ratios (ORs) with $95 \%$ confidence intervals (CIs) were pooled to estimate the prognostic role of NLR in patients with ICH. Poor functional outcome was defined as modified Rankin Scale $\geq 3$. Four studies with 1,720 patients were included. The pooled OR of higher NLR for poor functional outcome at 3 months was 2.74 (95\% CI, 1.33-5.65). The pooled OR of higher NLR for death at 3 months was 1.58 (95\% CI, 0.44-5.68). Subgroup analysis and sensitivity analysis were also performed. Publication bias was not present. In conclusion, for patients with ICH, higher NLR was associated with poorer functional outcome at 3 months, while higher NLR was not associated with higher risk of death at $\mathbf{3}$ months.

\section{INTRODUCTION}

Stroke is one of the leading causes of mortality and disability worldwide [1]. Intracerebral hemorrhage (ICH) is the second most common subtype of stroke and represents approximately $10 \%$ to $20 \%$ of all strokes [2]. ICH is characterized by high rates of mortality and disability, and little effective therapeutic strategies are available currently [3]. Apart from the nature of the hematoma, like volume and position [4-6], some other factors have been identified to be associated with the prognosis of ICH. High blood pressure in the acute phase was widely recognized to be associated with a poor outcome [7], and blood pressure variability has also been shown to predict poor outcome [8]. However the optimal treatment of high blood pressure after ICH is still controversial [9]. Some biochemical parameters, such as cholesterol and ferritin level, were also reported to be biomarkers of outcomes $[10,11]$. Besides, it has been suggested that brain imaging parameters may predict outcome in ICH patients, for example, satellite sign and blend sign in the initial CT scan $[12,13]$.

Recently, a growing body of evidence supports that inflammatory response plays a key role in ICH [1416]. In this context, some inflammatory markers were suggested to predict outcome in ICH, such as, leukocyte count, neutrophil count, lymphocyte count, neutrophil lymphocyte ratio (NLR), interleukin-6 and C-reactive protein [17]. Among them, NLR was heated studied. And NLR was found to have a prognostic role in various solid tumors and acute ischemic stroke $[18,19]$. In recent years, several studies investigating the prognostic role of NLR in ICH were published [20-23]. Some researchers found that higher NLR could predict worse short-term outcome 
in ICH $[20,22,23]$, however, Sun et al. did not come to such a conclusion [21].

Therefore, due to the controversy, we aimed to systematically evaluate the prognostic role of NLR in patients with $\mathrm{ICH}$ through performing a meta-analysis.

\section{RESULTS}

\section{Literature research}

The initial literature research retrieved 143 studies. Among them, 25 were duplicated and were removed. After screening for the titles and abstracts, 101 studies were excluded according to the predefined criteria. The rest 17 studies were reviewed in full text and 12 were further excluded due to unrelated or lacking enough data. Two studies were performed in the same institute, and the study periods overlapped $[17,22]$. Then, the study not adopting the widely used outcome measure was excluded [17]. Eventually, four articles were included in our study [2023]. The study selection process was shown in Figure 1.

\section{Study characteristics}

The main characteristics of the 4 included studies were shown in Table 1. All of them were published in the latest two years. Two studies were from China, one was from Germany and the other one was form Italy. A total of 1,720 patients were included (mean 430). The interval between onset and admission was within 24 hours or within 7 days (not reported in one study). Blood samples were collected on admission or on the second morning. The cut-off values of NLR were various. The outcome measures included poor functional outcome at 3 months and death at 3 months. All the ORs were adjusted.

\section{Overall analysis}

Three studies used poor functional outcome at 3 months as the outcome measure [20-22]. The pooled OR of the 3 studies was 2.74 (95\% CI, 1.33-5.65) (Figure 2), suggesting that higher NLR was associated with higher risk of poor functional outcome at 3 months in patients with ICH. Significant between-study heterogeneity was found $\left(\mathrm{I}^{2}=60.0 \%, \mathrm{P}=0.082\right)$. Sensitivity analysis revealed that the study by Lattanzi et al. [22] contributed greatly to the heterogeneity. After removing this study, the heterogeneity shrinked to $20.1 \%$ and the pooled OR remained statistically significant (OR 2.11; 95\% CI, 1.30-3.43).

Three studies used the outcome measure of death at 3 months $[20,21,23]$. The pooled OR of the 3 studies was 1.58 (95\% CI, 0.44-5.68) (Figure 3), indicating that higher NLR was not associated with higher risk of death at 3 months in patients with ICH. The between-study heterogeneity was also found $\left(\mathrm{I}^{2}=93.3 \%, \mathrm{P}<0.001\right)$. Sensitivity analysis identified that the study by Tao et al.
[22] was a significant contributor to the heterogeneity. After excluding this study, the heterogeneity turned sharply to $0 \%$, but the pooled OR was still not statistically significant (OR 0.97; 95\% CI, 0.95-1.00).

\section{Subgroup analysis}

As to the three studies examining functional outcome at 3 months, 2 were from China and 1 was from Italy. The pooled OR of the 2 studies from China was 2.11 (95\% CI, 1.30-3.43), and the OR of the study from Italy was 6.37 (95\% CI, 2.33-17.40). Two of the three studies included patients admitted within 24 hours from onset, and blood samples of the two studies were collected on admission. The pooled OR of the two studies was 3.71 (95\% CI, 1.57-8.75). The other study included patients admitted within 7 days from onset and collected blood samples on the second morning, and the OR of this study was 1.46 (95\% CI, 0.65-3.28).

As to the three studies examining death at 3 months, 2 were from China and 1 was from Germany. The pooled OR of the 2 studies from China was 2.02 (95\% CI, 0.27$15.25)$, and the OR of the study from Germany was 0.97 (95\% CI, 0.95-1.00). Two of the three studies collected blood samples on admission, and the pooled OR was 2.17 (95\% CI, 0.43-10.97). The other study collected blood samples on the second morning, and the OR was 0.64 (95\% CI, 0.15-2.76).

All the pooled results above were shown in Table 2.

\section{Publication bias}

No significant publication bias was found as to the 3 studies examining functional outcome at 3 months $(p=1.000)$ or the 3 studies examining death at 3 months $(p=1.000)$. The two Begg's plots of publication bias were shown in Figure 4.

\section{DISCUSSION}

This study intended to assess the prognostic value of NLR in patients with spontaneous ICH. We performed a meta-analysis to summarize the present evidence and four studies were included. To our best knowledge, this is the first meta-analysis on this issue. Our results showed that higher NLR was associated with poorer functional outcome at 3 months in patients with $\mathrm{ICH}$, while higher NLR was not correlated with higher risk of death at 3 months.

Subgroup analyses were also performed to evaluate the value of NLR in predicting functional outcome at 3 months in different settings. The pooled OR of the two studies from China and the OR of the study from Italy were both statistically significant, implying its applicability across countries. However, with a small sample size, caution must be applied. As to the two studies 
with patients admitted within 24 hours from onset and blood samples collected on admission, the pooled OR was significant, compared to the study with patients admitted within 7 days from onset and blood samples collected on the second morning. Giede-Jeppe et al. [23] found that, in patients with ICH, NLR increased at first, followed by decreasing, and then increased again after admission. The apex was at day $2(\mathrm{NLR}=5.76)$, and the nadir occurred at day $5(\mathrm{NLR}=4.66)$ [23]. The NLR also changes over time in patients with acute ischemic stroke [24]. Thus, most investigators used blood samples on admission. A future research direction may be exploring the prognostic role of dynamic NLRs in ICH.
With regards to the three studies examining death at 3 months, the overall OR and ORs in the subgroup were all not significant, suggesting that NLR may not be associated with mortality at 3 months in patients with $\mathrm{ICH}$. Wang et al. [15] assessed the predictive value of NLR in patients with ICH with the endpoint of 30-day mortality, and found that higher NLR exhibited significantly increased 30-day mortality. Therefore, due to the limited study number and significant heterogeneity, more studies are needed to further address the role of NLR in predicting short-term mortality.

Higher NLRs represent both elevated innate immune responses (elevated neutrophils) and decreased

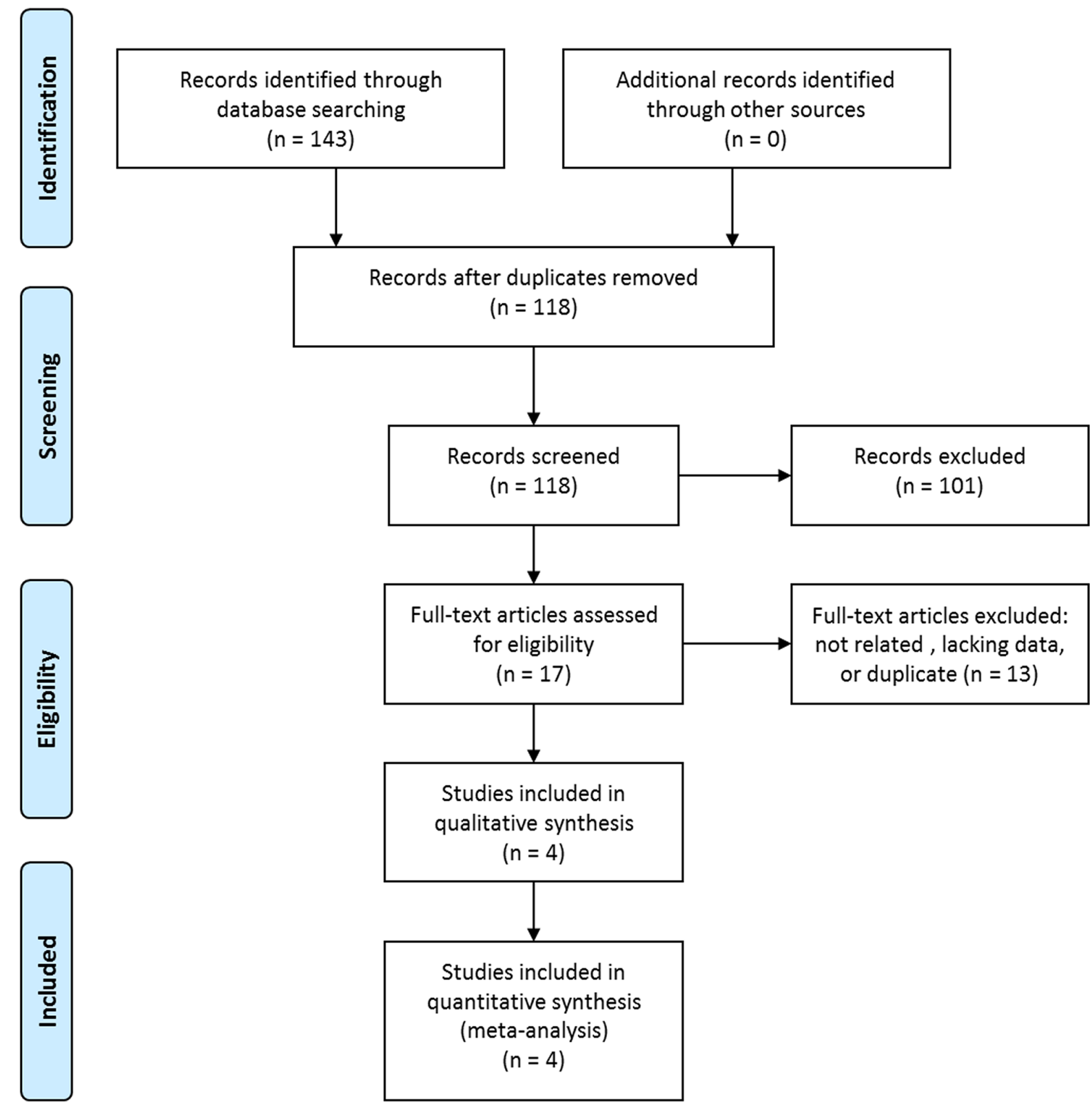

Figure 1: Selection process of studies. 
Table 1: Characteristics of the included studies

\begin{tabular}{|c|c|c|c|c|c|c|c|c|}
\hline Author & Year & Country & $\mathbf{N}(\mathbf{F} / \mathbf{M})$ & Age (yrs) & $\begin{array}{c}\text { Onset to } \\
\text { admission }\end{array}$ & Sample time & $\begin{array}{l}\text { Optimal cut- } \\
\text { off value }\end{array}$ & $\begin{array}{c}\text { Outcome } \\
\text { measure }\end{array}$ \\
\hline Tao & 2017 & China & $\begin{array}{c}336 \\
(120 / 216)\end{array}$ & mean 58.5 & $\leq 24$ hours & on admission & 6.62 & $\begin{array}{c}\text { death at } 3 \\
\text { months }\end{array}$ \\
\hline \multirow{3}{*}{ Sun } & \multirow{3}{*}{2017} & \multirow{3}{*}{ China } & \multirow{3}{*}{$\begin{array}{c}352 \\
(118 / 234)\end{array}$} & \multirow{3}{*}{ mean 64.2} & \multirow{3}{*}{$\leq 7$ days } & on admission & 6.28 & $\begin{array}{c}\text { mRS at } 3 \\
\text { months }\end{array}$ \\
\hline & & & & & & 2ed morning & NR & $\begin{array}{c}\text { death at } 3 \\
\text { months }\end{array}$ \\
\hline & & & & & & 2ed morning & NR & $\begin{array}{c}\mathrm{mRS} \text { at } 3 \\
\text { months }\end{array}$ \\
\hline $\begin{array}{l}\text { Giede- } \\
\text { Jeppe }\end{array}$ & 2017 & Germany & $\begin{array}{c}855 \\
(398 / 457)\end{array}$ & $\begin{array}{c}\text { median } 72.5 \\
(\mathrm{NLR} \geq 4.66) \\
\text { median } 71 \\
(\mathrm{NLR}<4.66)\end{array}$ & NR & on admission & 4.66 & $\begin{array}{c}\text { death at } 3 \\
\text { months }\end{array}$ \\
\hline Lattanzi & 2016 & Italy & $\begin{array}{c}177 \\
(114 / 63)\end{array}$ & mean 67.1 & $\leq 24$ hours & on admission & 4.58 & $\begin{array}{c}\mathrm{mRS} \text { at } 3 \\
\text { months }\end{array}$ \\
\hline
\end{tabular}

$\mathrm{N}(\mathrm{F} / \mathrm{M})$ : number of patients (female/male), yrs; years, NLR: neutrophil lymphocyte ratio, NR: not reported, mRS: modified Rankin Scale.

Study

ID

Tao (2017)
Sun (2017)
Lattanzi (2016)
Overall (I-squared $=60.0 \%, p=0.082$ )

NOTE: Weights are from random effects analysis

.0574
$\%$

ES $(95 \% \mathrm{Cl})$

Weight

Figure 2: Pooled odds ratio (OR) of higher neutrophil lymphocyte ratio (NLR) for poor functional outcome at 3 months in patients with intracerebral hemorrhage. 
Table 2: Summary of meta-analysis results

\begin{tabular}{|c|c|c|c|c|c|c|c|}
\hline & $\mathbf{N}$ & Model & Pooled OR (95\% CI) & P value & $\begin{array}{l}\text { Heterogeneity } \\
\left(\mathbf{I}^{2}, \mathbf{P}\right)\end{array}$ & Conclusion & $\begin{array}{c}\text { Publication } \\
\text { bias }\end{array}$ \\
\hline \multicolumn{8}{|l|}{$\begin{array}{l}\text { PFO at } 3 \\
\text { months }\end{array}$} \\
\hline Total & 3 & random & $2.74(1.33-5.65)$ & 0.006 & $60.0 \%, 0.082$ & positive & 1.000 \\
\hline China & 2 & fixed & $2.11(1.30-3.43)$ & 0.002 & $20.1 \%, 0.263$ & positive & \\
\hline Italy & 1 & - & $6.37(2.33-17.40)$ & - & - & positive & \\
\hline $\begin{array}{l}\text { Onset to } \\
\text { admission } \leq \\
24 \mathrm{~h}\end{array}$ & 2 & random & $3.71(1.57-8.75)$ & 0.003 & $55.4 \%, 0.135$ & positive & \\
\hline $\begin{array}{l}\text { Onset to } \\
\text { admission } \\
\leq 7 \mathrm{~d}\end{array}$ & 1 & - & $1.46(0.65-3.28)$ & - & - & negative & \\
\hline $\begin{array}{l}\text { Sample time- } \\
\text { on admission }\end{array}$ & 2 & random & $3.71(1.57-8.75)$ & 0.003 & $55.4 \%, 0.135$ & positive & \\
\hline $\begin{array}{l}\text { Sample } \\
\text { time-on } 2 \text { ed } \\
\text { morning }\end{array}$ & 1 & - & $1.46(0.65-3.28)$ & - & - & negative & \\
\hline \multicolumn{8}{|l|}{$\begin{array}{l}\text { Death at } 3 \\
\text { months }\end{array}$} \\
\hline Total & 3 & random & $1.58(0.44-5.68)$ & 0.486 & $93.3 \%,<0.001$ & negative & 1.000 \\
\hline China & 2 & random & $2.02(0.27-15.25)$ & 0.496 & $85.0 \%, 0.010$ & negative & \\
\hline Germany & 1 & - & $0.97(0.95-1.00)$ & - & - & negative & \\
\hline $\begin{array}{l}\text { Sample time- } \\
\text { on admission }\end{array}$ & 2 & random & $2.17(0.43-10.97)$ & 0.350 & $96.6 \%,<0.001$ & negative & \\
\hline $\begin{array}{l}\text { Sample } \\
\text { time-on 2ed } \\
\text { morning }\end{array}$ & 1 & - & $0.64(0.15-2.76)$ & - & - & negative & \\
\hline
\end{tabular}

PFO: poor functional outcome, N: number of included studies, OR: odds ratio, CI: confidence interval.

adaptive immune responses (decreased lymphocytes) [25]. After $\mathrm{ICH}$, neutrophils are recruited around the hematoma quickly $[22,26]$. It has been demonstrated in a mouse model that neutrophil infiltration into the site of hemorrhage induces secondary brain damage [27]. Among patients with ICH, higher peripheral blood neutrophil counts were found to be independently related to poor short-term outcome $[20,22]$. Acute central nervous system injury also induces the apoptosis and functional deactivation of lymphocytes [28], which greatly impairs host defense [23]. This may lead to in-hospital infectious complications [22, 23], which are a leading cause of morbidity and mortality in patients with ICH [28]. GiedeJeppe et al. [23] showed that patients with increased NLR may be associated with higher risk of developing a sepsis and increased short-term mortality.

NLR is a readily accessible and inexpensive marker. In line with some previous studies, our results demonstrated that higher NLR could be a predictor for poor outcome in ICH $[20,22]$, which could be applied in clinical work. Moreover, as we mentioned above, many other factors were correlated with the outcome of ICH patients. And many of them were controllable, for example, blood pressure and some biochemical parameters. These controllable parameters, as well as inflammatory responses modulation, may represent potential therapeutic targets. Besides, with regards to prognosis, it is promising to perform multidimensional assessment of the known markers and improve prognostic algorithms.

Significant between-study heterogeneities were observed in the meta-analysis. As to the three studies examining functional outcome at 3 months, after excluding the study by Lattanzi et al. [22], the heterogeneity shrinked from $60.0 \%$ to $20.1 \%$ and the pooled OR remained statistically significant. As to the three studies examining death at 3 months, after removing the study contributed greatly to the 
heterogeneity [20], the heterogeneity turned form $93.3 \%$ to $0.0 \%$ but the pooled OR was still not statistically significant. The potential sources of heterogeneity might be from different patient sources, different admission time, different blood collection time and different cut-off values NLR. We did subgroup analyses according to the factors but heterogeneity could not be eliminated by these attempts.
There are several limitations in this meta-analysis. First and foremost, the number of included studies was only four. The number of studies in every subgroup was also limited. These results therefore need to be interpreted with caution. Secondly, some baseline characteristics were different among the studies, such as, the admission time, the blood collection time and the cut-off values NLR. Besides,
Study

ID
$\%$

ES $(95 \% \mathrm{Cl}) \quad$ Weight

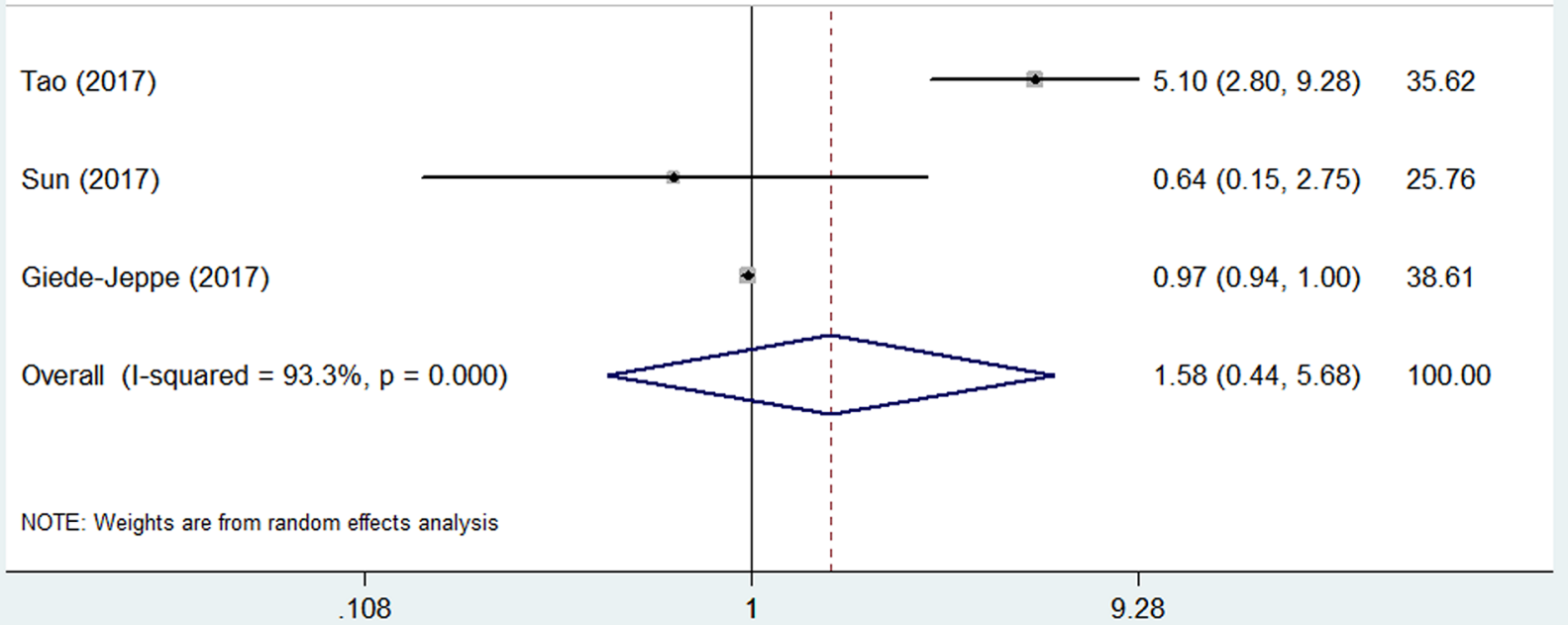

Figure 3: Pooled odds ratio (OR) of higher neutrophil lymphocyte ratio (NLR) for death at 3 months in patients with intracerebral hemorrhage.
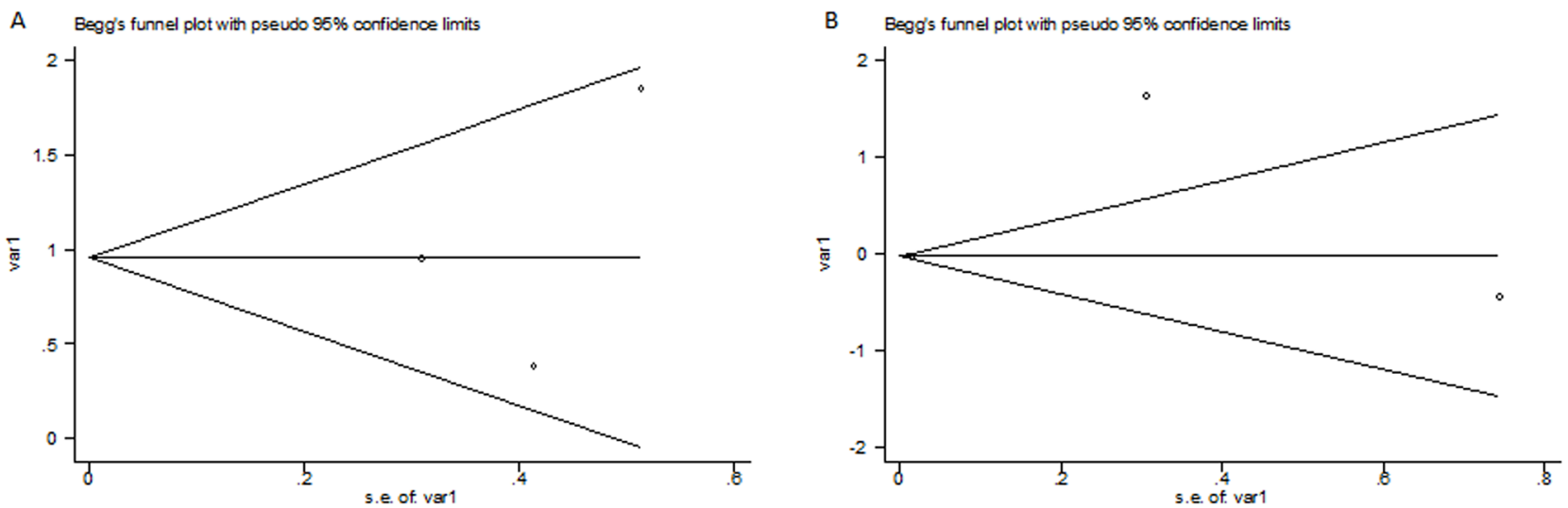

Figure 4: The Begg's publication bias plots of the 3 studies examining functional outcome at 3 months (A) and the 3 studies examining death at 3 months (B). 
significant between-study heterogeneities were observed and random effects models were used. Furthermore, no significant publication bias was found in this meta-analysis, but publication bias was a major concern for all metaanalyses and should not be excluded completely.

In conclusion, our results demonstrated that, in patients with ICH, higher NLR was associated with poorer functional outcome at 3 months, while higher NLR was not correlated with higher risk of death at 3 months. As a readily accessible and inexpensive marker, NLR could be applied in the prognosis of ICH with other known markers. The findings also revealed that early intervention regarding inflammatory responses modulation may be a promising therapy in patients with ICH. However, more studies are needed to further address this issue and elucidate the underlining mechanisms.

\section{MATERIALS AND METHODS}

\section{Search strategy}

We followed the developed guidelines for systematic reviews and meta-analyses in performing our metaanalysis [29]. PubMed, EMBASE, Web of Knowledge, Cochrane Library and China National Knowledge Infrastructure (CNKI) were searched for potentially relevant literature (last search ran on May 18th, 2017). The following keywords were used: 'neutrophil lymphocyte ratio' AND 'intracranial hemorrhages'. The reference lists of relevant articles were also screened for additional studies. No language restrictions were used.

\section{Study selection}

Two investigators (J.Z. and S.Z.) independently determined study eligibility, with any disagreements being discussed. Studies were included according to the following inclusion criteria: (1) the patients were diagnosed with spontaneous ICH; (2) blood samples were collected after admission, and NLR was calculated; (3) patients were followed up for survival outcomes or functional outcomes; (4) enough data was reported to estimate the prognostic role of NLR in patients with ICH. Unrelated articles, reviews, case reports, letters, conference abstracts, and studies without enough data were excluded.

\section{Data extraction}

Two researchers (J.Z. and S.Z.) extracted data from the included studies independently, and discrepancies were resolved by consensus. The primary data was odds ratio (OR) with $95 \%$ confidence interval (CI) for poorer outcomes. Adjusted OR was extracted if adjusted OR and unadjusted OR were both reported. The study and patient characteristics were also extracted, including first author, publication year, patient source, number of patients, mean or median age of patients, interval between onset and admission, sampling time of blood and the cut-off value of NLR.

\section{Statistical analysis}

Poor functional outcome was defined as major disability or death (modified Rankin Scale $[\mathrm{mRS}] \geq 3$ ) [30]. The $\log \mathrm{OR}$ and variance, calculated from the OR and $95 \% \mathrm{CI}$, were used for aggregation. Forest plots were outlined to estimate the pooled prognostic role of NLR in patients with ICH. The pooled OR was considered statistically significant with the $\mathrm{p}$ value less than 0.05 and the $95 \%$ CI not overlapping 1. Subgroup analyses were also performed according to patient source, interval between onset and admission, and sampling time of blood. The between-study heterogeneity was assessed, with $\mathrm{P}<0.10$ or $\mathrm{I}^{2}>50 \%$ indicating significant heterogeneity [31]. If heterogeneity was present, random effects models were used. Then, sensitivity analysis was performed to assess the contribution of each study to heterogeneity by excluding individual studies one at a time. Publication bias was assessed by Begg's test and $p>0.05$ was considered that there was no potential publication bias. All the above statistical analyses were performed by STATA 11.0 (STATA Corporation, College Station, TX).

\section{ACKNOWLEDGMENTS}

We would like to thank the reviewers for their constructive comments.

\section{CONFLICTS OF INTEREST}

The authors declare no conflicts of interests.

\section{FUNDING}

National Key Technology Research and Development Program of the Ministry of Science and Technology of China (Neurosurgery research for brain tumor, 2014BAI04B01).

\section{REFERENCES}

1. Johnston SC, Mendis S, Mathers CD. Global variation in stroke burden and mortality: estimates from monitoring, surveillance, and modelling. Lancet Neurol. 2009; 8: 34554. https://doi.org/10.1016/S1474-4422(09)70023-7.

2. Ikram MA, Wieberdink RG, Koudstaal PJ. International epidemiology of intracerebral hemorrhage. Curr Atheroscler Rep. 2012; 14: 300-6. https://doi.org/10.1007/ s11883-012-0252-1.

3. Hemphill JC 3rd, Greenberg SM, Anderson CS, Becker K, Bendok BR, Cushman M, Fung GL, Goldstein JN, 
Macdonald RL, Mitchell PH, Scott PA, Selim MH, Woo $\mathrm{D}$, et al. Guidelines for the management of spontaneous intracerebral hemorrhage: a guideline for healthcare professionals from the American Heart Association/ American Stroke Association. Stroke. 2015; 46: 2032-60. https://doi.org/10.1161/STR.manuscriptmanuscript0069.

4. Broderick JP, Brott TG, Duldner JE, Tomsick T, Huster G. Volume of intracerebral hemorrhage. A powerful and easy-to-use predictor of 30-day mortality. Stroke. 1993; 24: 987-93.

5. Dowlatshahi D, Demchuk AM, Flaherty ML, Ali M, Lyden PL, Smith EE; VISTA Collaboration. Defining hematoma expansion in intracerebral hemorrhage: relationship with patient outcomes. Neurology. 2011; 76: 1238-44. https:// doi.org/10.1212/WNL.0b013e3182143317.

6. Hemphill JC 3rd, Bonovich DC, Besmertis L, Manley GT, Johnston SC. The ICH score: a simple, reliable grading scale for intracerebral hemorrhage. Stroke. 2001; 32: 891-7.

7. Lattanzi S, Silvestrini M, Provinciali L. Elevated blood pressure in the acute phase of stroke and the role of Angiotensin receptor blockers. Int J Hypertens. 2013; 2013: 941783. https://doi.org/10.1155/2013/941783.

8. Lattanzi S, Cagnetti C, Provinciali L, Silvestrini M. Blood pressure variability and clinical outcome in patients with acute intracerebral hemorrhage. J Stroke Cerebrovasc Dis. 2015; 24: 1493-9. https://doi.org/10.1016/j.jstrokecerebrov asdis.2015.03.014.

9. Lattanzi S, Cagnetti C, Provinciali L, Silvestrini M. How should we lower blood pressure after cerebral hemorrhage? A systematic review and meta-analysis. Cerebrovasc Dis. 2017; 43: 207-13. https://doi.org/10.1159/000462986.

10. Garton AL, Gupta VP, Christophe BR, Connolly ES Jr. Biomarkers of functional outcome in intracerebral hemorrhage: interplay between clinical metrics, CD163, and ferritin. J Stroke Cerebrovasc Dis. 2017; 26: 1712-20. https://doi.org/10.1016/j.jstrokecerebrovasdis.2017.03.035.

11. Chen YW, Li CH, Yang CD, Liu CH, Chen CH, Sheu JJ, Lin SK, Chen AC, Chen PK, Chen PL, Yeh CH, Chen JR, Hsiao YJ, et al. Low cholesterol level associated with severity and outcome of spontaneous intracerebral hemorrhage: results from Taiwan Stroke Registry. PLoS One. 2017; 12: e0171379. https://doi.org/10.1371/journal.pone.0171379.

12. Sporns PB, Schwake M, Schmidt R, Kemmling A, Minnerup J, Schwindt W, Cnyrim C, Zoubi T, Heindel W, Niederstadt T, Hanning U. Computed tomographic blend sign is associated with computed tomographic angiography spot sign and predicts secondary neurological deterioration after intracerebral hemorrhage. Stroke. 2017; 48: 131-5. https://doi.org/10.1161/STROKEAHA.116.014068.

13. Shimoda Y, Ohtomo S, Arai H, Okada K, Tominaga T. Satellite sign: a poor outcome predictor in intracerebral hemorrhage. Cerebrovasc Dis. 2017; 44: 105-12. https:// doi.org/10.1159/000477179.
14. Wang J. Preclinical and clinical research on inflammation after intracerebral hemorrhage. Prog Neurobiol. 2010; 92: 463-77. https://doi.org/10.1016/j.pneurobio.2010.08.001.

15. Wang F, Hu S, Ding Y, Ju X, Wang L, Lu Q, Wu X. Neutrophil-to-lymphocyte ratio and 30-day mortality in patients with acute intracerebral hemorrhage. J Stroke Cerebrovasc Dis. 2016; 25: 182-7. https://doi.org/10.1016/j. jstrokecerebrovasdis.2015.09.013.

16. Morotti A, Phuah CL, Anderson CD, Jessel MJ, Schwab K, Ayres AM, Pezzini A, Padovani A, Gurol ME, Viswanathan A, Greenberg SM, Goldstein JN, Rosand J. Leukocyte count and intracerebral hemorrhage expansion. Stroke. 2016; 47: 1473-8. https://doi.org/10.1161/strokeaha.116.013176.

17. Lattanzi S, Cagnetti C, Provinciali L, Silvestrini M. Neutrophilto-lymphocyte ratio and neurological deterioration following acute cerebral hemorrhage. Oncotarget. 2017; 8: 57489-94. https://doi.org/10.18632/oncotarget.15423.

18. Templeton AJ, McNamara MG, Seruga B, Vera-Badillo FE, Aneja P, Ocana A, Leibowitz-Amit R, Sonpavde G, Knox JJ, Tran B, Tannock IF, Amir E. Prognostic role of neutrophil-to-lymphocyte ratio in solid tumors: a systematic review and meta-analysis. J Natl Cancer Inst. 2014; 106: dju124. https://doi.org/10.1093/jnci/dju124.

19. Qun S, Tang Y, Sun J, Liu Z, Wu J, Zhang J, Guo J, Xu Z, Zhang D, Chen Z, Hu F, Xu X, Ge W. Neutrophil-tolymphocyte ratio predicts 3-month outcome of acute ischemic stroke. Neurotox Res. 2017; 31: 444-52. https:// doi.org/10.1007/s12640-017-9707-z.

20. Tao C, Hu X, Wang J, Ma J, Li H, You C. Admission neutrophil count and neutrophil to lymphocyte ratio predict 90-day outcome in intracerebral hemorrhage. Biomark Med. 2017; 11: 33-42. https://doi.org/10.2217/bmm-2016-0187.

21. Sun Y, You S, Zhong C, Huang Z, Hu L, Zhang X, Shi J, Cao Y, Liu CF. Neutrophil to lymphocyte ratio and the hematoma volume and stroke severity in acute intracerebral hemorrhage patients. Am J Emerg Med. 2017; 35: 429-33. https://doi.org/10.1016/j.ajem.2016.11.037.

22. Lattanzi S, Cagnetti C, Provinciali L, Silvestrini M. Neutrophil-to-lymphocyte ratio predicts the outcome of acute intracerebral hemorrhage. Stroke. 2016; 47: 1654-7. https://doi.org/10.1161/strokeaha.116.013627.

23. Giede-Jeppe A, Bobinger T, Gerner ST, Sembill JA, Sprugel MI, Beuscher VD, Lucking H, Hoelter P, Kuramatsu JB, Huttner HB. Neutrophil-to-lymphocyte ratio is an independent predictor for in-hospital mortality in spontaneous intracerebral hemorrhage. Cerebrovasc Dis. 2017; 44: 26-34. https://doi.org/10.1159/000468996.

24. Guo Z, Yu S, Xiao L, Chen X, Ye R, Zheng P, Dai Q, Sun W, Zhou C, Wang S, Zhu W, Liu X. Dynamic change of neutrophil to lymphocyte ratio and hemorrhagic transformation after thrombolysis in stroke. J Neuroinflammation. 2016; 13: 199. https://doi.org/10.1186/ s12974-016-0680-x. 
25. Brooks SD, Spears C, Cummings C, VanGilder RL, Stinehart KR, Gutmann L, Domico J, Culp S, Carpenter J, Rai A, Barr TL. Admission neutrophil-lymphocyte ratio predicts 90 day outcome after endovascular stroke therapy. J Neurointerv Surg. 2014; 6: 578-83. https://doi.org/10.1136/ neurintsurg-2013-010780.

26. Aronowski J, Zhao X. Molecular pathophysiology of cerebral hemorrhage: secondary brain injury. Stroke. 2011; 42: 1781-6. https://doi.org/10.1161/ STROKEAHA.110.596718.

27. Sansing LH, Harris TH, Kasner SE, Hunter CA, Kariko K. Neutrophil depletion diminishes monocyte infiltration and improves functional outcome after experimental intracerebral hemorrhage. Acta Neurochir Suppl. 2011; 111: 173-8. https://doi.org/10.1007/978-3-7091-0693-8_29.

28. Meisel C, Schwab JM, Prass K, Meisel A, Dirnagl U. Central nervous system injury-induced immune deficiency syndrome. Nat Rev Neurosci. 2005; 6: 775-86. https://doi. org/10.1038/nrn1765.

29. Moher D, Shamseer L, Clarke M, Ghersi D, Liberati A, Petticrew M, Shekelle P, Stewart LA. Preferred reporting items for systematic review and meta-analysis protocols (PRISMA-P) 2015 statement. Syst Rev. 2015; 4: 1. https:// doi.org/10.1186/2046-4053-4-1.

30. Banks JL, Marotta CA. Outcomes validity and reliability of the modified Rankin scale: implications for stroke clinical trials: a literature review and synthesis. Stroke. 2007; 38: 1091-6. https://doi.org/10.1161/01. STR.0000258355.23810.c6.

31. Higgins JP, Thompson SG, Deeks JJ, Altman DG. Measuring inconsistency in meta-analyses. BMJ. 2003; 327: 557-60. https://doi.org/10.1136/bmj.327.7414.557. 